International Journal of Bilingualism, Vol. 5, No. 1 (March) 2001, pp. 1-17

\title{
TOWARDS A DESCRIPTION OF TRILINGUAL COMPETENCE
}

Charlotte Hoffmann, University of Salford

\section{Acknowledgements}

My thanks are due to the two anonymous reviewers for their helpful comments and suggestions. I also thank Dr Rosa Manchón of the University of Murcia who undertook a critical revision of a previous draft.

\begin{abstract}
Most studies involving trilingualism have been carried out within the theoretical framework of bilingualism research. No attempt has been made to delimit trilingualism as a concept in its own right, and often it has been assumed to be an extension of bilingualism. In young children, trilingual language acquisition largely follows the path of bilingual acquisition. With regard to language behaviour there are again similarities, but certain differences can be observed. As an overview of studies of individual trilingualism, the present article aims to provide a framework for the discussion. Models of bilingual language competence serve as a starting point to an investigation of possible defining features of trilingual competence. Of particular interest are the pragmatic component of language competence; the trilingual's ability to make appropriate linguistic choices in monolingual/bilingual/trilingual communication modes; and observed code-switching. The question of how and when a trilingual's languages become activated or deactivated leads to a consideration of language processing and metalinguistic awareness. In the absence of research involving trilinguals, bilingual models are examined with a view to pointing out possible similarities and differences. It is suggested that these are both of a quantitative and qualitative kind, and therefore trilingual competence is distinct from bilingual competence.
\end{abstract}

\section{Introduction}

It is suggested here that trilingualism can be seen as a distinct area of research. Although the relatively scant amount of empirical and experimental work on trilinguals does not as yet permit the establishment of explanatory models it is possible now to distinguish broad trends of investigation and to approach the description of particular aspects of trilingualism from a variety of angles. The wider context of this article is to provide an overview of trilingualism studies and to point the way to possible profitable areas of investigation. Its more specific concern is with a theoretical issue: to consider linguistic competence in trilingual children in terms of how it manifests itself and how it might be explained. It is generally accepted that certain qualitative as well as quantitative differences exist between the linguistic competence of 
monolingual and bilingual children. In the absence of a sizeable corpus of data from trilingual subjects' language and language use, a comparison of bilingual and trilingual competence cannot go beyond a preliminary characterisation of the respective competences in relation to one another. The hypothesis is that apart from quantitative differences we may find relatively few differences in kind, and that certain social, cultural and, above all, psychological and personality-related factors may assume disproportionately high significance in influencing trilingual competence, as compared with their influence in the case of bilingual competence.

\section{Definitions concepts and classifications}

To my knowledge no authoritative definition of trilingualism has been attempted - perhaps not even considered important. One may assume that apart from the presence of three languages in one speaker other aspects which are involved in trilingualism are equally variable in trilingualism as is the case with bilingualism. Baetens Beardsmore's (1982) remark on the "open ended semantics" of bilingualism as a concept can easily be made in relation to trilingualism as well. Many proposed definitions of bilingualism refer explicitly to two languages, but sometimes it is suggested that what is said about bilingualism is equally applicable to "two or more languages" - see, for instance, Oksaar's definition of bilingualism: "the ability of a person to use here and now two or more languages as a means of communication in most situations and to switch from one language to the other if necessary" (1983: 19). Similarly, Skutnabb-Kangas (1984) allows for more than two languages to be present in the person she defines as bilingual. Indeed, the implicit suggestion that several lingualisms can be subsumed under the concept of bilingualism is illustrated in an early work in the history of such studies: Haugen refers to multilingualism as "a kind of multiple bilingualism" (1956: 9). This practice seems not to have been challenged, and studies that involve subjects who were acquiring more than two languages have worked within the theoretical framework of bilingualism with regard to the collection of data as well as its analysis.

Scholars looking at issues dealing, for example, with language contact, language planning or bilingual education have at times preferred to employ the term "multilingualism" (rather than "bilingualism") so as to distinguish clearly the macrolinguistic from the microlinguistic level of investigation. Moreover, it encompasses the idea that not only is more than one language involved, but also any number of linguistic varieties may be present in the particular 
sociolinguistic situation under consideration. As research has moved on we have also seen an increase in the use of this term in psycholinguistic studies of second and third language acquisition and bilingualism. Cenoz and Genesee (1998) describe multilingualism as the final result of the process of acquisition of several non-native languages, thereby clearly making it an attribute of the individual, and Jeßner (1997) too sees multilingualism as a variant of bilingualism in her discussion of linguistic variability in individuals. Although she writes mainly from a perspective of second language acquisition and bilingualism, she does look beyond at learners acquiring third or fourth languages, and in this context employs the term multilingualism. With regard to terminology, then, there are no clear delimitations between bilingualism and multilingualism. With respect to trilingualism the number of languages involved is obviously clearly specified but should one otherwise assume that it simply represents an extension of bilingualism? It obviously shares a number of features with both bilingualism and multilingualism, while at the same time retaining characteristics of its own. Some of these specific characteristics are addressed later on.

Present knowledge about bilingual competence has been derived from insights gained from investigations into a number of different fields, such as bilingual language acquisition and language processing, comparisons of the language output of monolinguals and bilinguals, and attempts to explain the relationship that is known to exist between the bilingual's two codes as manifested in phenomena like code-switching. There is considerable agreement about the similarities and the differences between monolingual and bilingual language acquisition and development, and this has led to the view that there are certain differences between the resulting linguistic competence. Grosjean's holistic view of bilingualism (1985 and 1992) espouses the idea that the bilingual speaker should not be considered as the aggregate of two complete (or perhaps incomplete) monolinguals, but as someone "with a unique and specific linguistic configuration" (1985: 470). Although these ideas were not entirely new (see, for instance, Oksaar 1973, 1977), Grosjean's model is presented in a particularly clear manner and has found widespread acceptance.

In a related discipline, second language acquisition, a similar view has been expressed with the establishment of the concept of "multicompetence". Cook defines it as "the compound state of a mind with two grammars" (Cook 1991 and 1992: 557-8). Cook's work arose out of technical questions that he had asked within Universal Grammar theory, but he presents the evidence for multicompetence from a range of areas. The difference between monocompetence and 
multicompetence is not only one of degree, he argues, but also one of kind as multicompetent speakers have a different knowledge of their languages from that possessed by monolinguals. So linguistic factors influence trilingual competence, but the discussion needs also to be mindful of metalinguistic and attitudinal factors which have been shown to have a bearing on bilingual competence as it is likely that they will prove to be influential in the trilingual as well.

In what follows a distinction is made between five groups of trilinguals, taking into account both the circumstances and the social context under which they become users of three languages. This distinction is made for methodological purposes and it is based on the trilingualism studies surveyed below. It is fully acknowledged that trilinguals vary from one another in many different ways, and that the word "trilingual" can only be used as a blanket term. Similarly, it is recognised that other criteria such as age or sequence or degree of competence could have been chosen resulting in a different typology.

(i) trilingual children who are brought up with two home languages which are different from the one spoken in the wider community;

(ii) children who grow up in a bilingual community and whose home language (either that of one or both parents) is different from the community languages;

(iii) third language learners, i.e. bilinguals who acquire a third language in the school context;

(iv) bilinguals who have become trilingual through immigration, and

(v) members of trilingual communities.

Needless to say, there are many individuals who straddle these categories or who in the course of their lives move from one to another. Motivational and attitudinal factors may play a more predictable role in the case of groups (iii) and (iv), while psychological and personality-related factors may assume greater importance in the first two groups. The following literature overview covers trilinguals which fall into the first four groups. The discussion of trilingual competence uses insights gained from primarily group (i) and (iv)trilinguals. Two facts clearly restrict this study: firstly, it is Eurocentric in that virtually all studies of trilingual language acquisition with which I am familiar involve different combinations of European languages. 
Secondly, I have deliberately excluded group (v) trilinguals, the most numerous group. Linguistic diversity in African and Asian countries brings about many different linguistic constellations, many of which have been reported on from sociolinguistic or educational perspectives rather than with the focus on individual trilingualism.

\section{Some studies on individual trilingualism}

Relatively few such studies have been completed so far, but we are beginning to see more, and also collaborative research projects which examine groups of trilinguals, for instance with regard to their language use or educational aspects. Three broad types of studies into trilingualism can be distinguished:

\subsection{Trilingual language acquisition in children}

Firstly, there are case studies of children who have become trilingual because they grew up in an environment where, between home and community, three languages were used. Sometimes these studies are just short reports on how the children of a particular family became trilingual, together with some comments about difficulties encountered maintaining the three languages. For instance, Arnberg (1987) describes a family in Sweden where the mother spoke Finnish and the father Kurdish to the children, whereas both parents used Swedish to each other. Swedish was the language of their social environment, and it was spoken by those of native as well as non-native background. When the father had to move to another part of the country the children's knowledge of Kurdish decreased rapidly until they became, in effect, bilingual speakers with a tricultural background. Harding and Riley (1986) have an example of trilingualism among the bilingual case studies they present. Theirs is the story of a bilingual French-German family who moved to a Portuguese-speaking country and whose child acquired Portuguese from the nanny, apart from French and German from the parents. The authors comment on the subject's proficiency in the three languages, saying that it reflects relative use and exposure. In Brazil, Portuguese was the subject's best language as it was the language he needed most and heard around him most often. But after the family returned to France he dropped Portuguese and soon, the authors observe, French became the strongest language. Both cases represent examples of transient trilingualism. 
Elwert's (1973) study, first published in 1959, is unusual in that it is a case of self-report. Elwert, a philologist rather than modern linguist, describes his own bilingual upbringing in Italy where he was exposed to two languages from birth. His parents (father German, mother English) spoke English to each other and addressed the child in English, as did also some of the parents' friends; other people talked in Italian to him, as did the maid (although she spoke a local, non-standard variety). The subject came into contact with some German while he was still in Italy, but he was not conscious of having acquired any German until the family moved to Germany and he entered school there at the age of 9, and then he acquired oral and literacy skills in German simultaneously. Elwert discusses at length the relative importance German and Italian had for him at certain stages in his life, debating the various factors which had a bearing on fluency, preference and dominance, the most important ones being time and place. This variability occurred with regard to the language of daily interaction - he claims that his best language at any particular time was the language of the environment in which he was immersed (“... in deren Milieu ich mich eine geraume Zeit befinde", 1973: 60). In relation to the use of the language of inner functions such as counting or reasoning, he also observes variable patterns depending on where he was, who he was with and what he was thinking of. It is interesting to see that Elwert throughout his study talks about bilingualism - first referring to English and Italian, later mainly with German and Italian in mind. It seems that when he became fully trilingual, i.e. when the language of his environment was German, English became the language of communication with his mother and also the vehicle for some of his reading. It was thus assigned a stable role in his life. In spite of his professed love of English and English literature, his other two languages appear to have preoccupied him much more, perhaps because of their fluctuating dominance. I have found this to be a recurrent pattern of trilingualism: it is seldom the case that three languages are of equal importance to the individual, and one of them eventually tends to become the least used one. Elwert's study is, of course, entirely subjective, and it was written from the perspective of an adult. Nevertheless, it makes an interesting contribution to the literature on two counts: firstly, it provides a truly long-term account of life with three languages ranging from early childhood to middle age; and secondly, his self portrait offers an 'insider view' of the role each of the three languages played for a trilingual person. He gives insights into psychological forces influencing aspects of language choice, dominance and preference, and how these may change over time.

In the literature there are only a small number of long-term trilingual studies, and none of them is comparable in scope and depth to well-known bilingual ones. In 1985 I reported on the 
language acquisition of two trilingual children using data collected over a seven-year period (Hoffmann 1985). The article was concerned mainly with aspects of language development and use, and with psychological and socio-cultural issues which seemed to have played an important role in the children's acquisition of Spanish, German and English. At that time the subjects' language use reflected the linguistic constellation in the family: German and Spanish were the languages used with the parents, other members of the family and many visitors, and English was the language of the community, school and peergroup friends. The children had not encountered negative attitudes towards their trilingualism or their languages, and they had developed sufficient competence in all three languages to fulfil their communication needs as they were at the time. Another study (Helot 1988) looked at two families with two children in each being brought up trilingually (with French, English and Irish). The author focused on the function each of the languages assumed for the subjects in the two families, who were observed in a variety of situations. In the case of one family, the relative importance and use of each language changed depending on whether they were in Dublin (English), France (French) or the Gaeltacht (an Irish-speaking environment). The pattern of language use of the second family was more stable and less complex, as English was never spoken in the home. In both families the pattern of language use reflected the degree of the children's linguistic competence at the time; as in the previous study, language choice was determined by the linguistic realities of the children's lives.

The studies mentioned so far contain very little trilingual linguistic data, i.e. examples of speech showing elements of all three languages. In some of my work (Hoffmann, 1985, 1991) I have presented a number of examples, including some instances of mixing and code-switching. Each of these includes elements from two languages rather than three, and there are examples of different combinations of the three languages. A later paper (Hoffmann 1992) discusses a longer conversation with a young Spanish-German-English trilingual child. It was recorded when the child was 2.9 and had had four months' contact with English. She was trying to get her English interlocutor who was also a proficient speaker of Spanish to join in an imaginary game, but this adult did not understand her game and explanations and was not very cooperative. The child had used English with German lexical and phonetic mixes throughout, but then she ended the conversation about the game changing the topic and uttering a sentence in Spanish, which she then repeated slowly and deliberately. Whether this was meant to produce a particular effect or whether the child switched because she felt that she was not getting very far using her weakest language, English, is of course impossible to tell. But the example shows that 
the child was aware of having at least two languages at her disposal, English and Spanish, while she might have been unaware of mixing lexical items from German, the cognate language, into her English.

Oksaar (1977) reported on her Estonian-Swedish bilingual son's acquisition of his $\mathrm{L}_{3}$, German, at age 3.11. At that time the child had already acquired the basic rules of linguistic and communicative competence. The convergence of internal and external influences on his third language acquisition was obviously different from what it had been when his bilingualism was established. Oksaar compares similarities and differences in the two acquisition processes and finds that the greatest similarities could be noted on the phonetic and paralinguistic levels: the child acquired the pronunciation of each of the three languages without deviations. Indeed, some of the examples given demonstrate that the child was quite aware of subtle pronunciation differences between German and Swedish words. The greatest differences were in the scope, succession and type of linguistic elements acquired in German. The child produced the kind of linguistic complexity which can be expected from a 3-4 year old: blocks of words, a number of features belonging to noun and verb morphology, the full range of verb tenses, all acquired within a short period of time. Clearly, the subject had made use of his linguistic experience of $\mathrm{L}_{1}$ and $\mathrm{L}_{2}$ when he developed his $\mathrm{L}_{3}$ subsequently. Oksaar's particular concern is codeswitching and the role it plays in the acquisition process of the child's three languages. For her the term seems to cover code choice, inter- and intrasentential code-switching and borrowing, and she adduces examples to show how the subject uses code-switching for certain functions, such as calling attention and seeking clarification, as well as for filling any lexical gaps - the latter being also discussed in terms of transfers and loan translations. Oksaar found evidence of transfer on the lexical level between the subject's first two languages (e.g. in the form of morphological transfers of Estonian verb endings on Swedish verbs) and also of semantic extension between one of the first two languages into the third language. These findings tell us something about trilingual acquisition and language processing in the trilingual child, and even though the focus of the study lay elsewhere Oksaar gives an interesting account of the child's developing linguistic repertoire which she refers to as Lx which is made up of rules and elements from L1, L2, L3 as well as containing elements and rules typical for Lx only. Again it can be observed that none of the examples given involve elements from all three languages in the same utterance. 
A recent study in which I was involved (Hoffmann and Widdicombe 1998) used data based on the speech of a trilingual boy aged 4.4. The boy's mother uses English only in the home (to both her child and her husband), his father uses Italian only (to the boy and his wife), and the language of the community is French. Both parents are trilingual and the child has had many opportunities to hear them function in the three different languages. The child has had prolonged contact with all three languages since birth.Ten hours of audio recording of conversation between mother and child where the base language was English yielded 174 instances of coining or code-switching overall, involving both French and Italian, but only 12 examples were of so-called "combination switches". i.e. utterances containing French and Italian switches within the same utterance, and in some instances the child was simply repeating the same item first in the one and then in the other non-base language. The study focused on developmental aspects of trilingual language behaviour and threw up some intriguing questions about language dominance and switching behaviour.

As will have become clear, these case studies differ quite considerably with regard to their subjects, languages and methodologies. But it is possible to extract some general features. For example, in most cases the subject had two first languages which he or she acquired from the parents, and then the third language, that of the community, was added while the child was still quite young. In all cases different languages were associated with different persons and/or situations identified by the subjects using the correct language to address their interlocutors. "Extroverts", that is, children of an outgoing and gregarious nature and a love of talking, coped particularly well. However, judgements were made when the children concerned were still quite young and their language development incomplete. We need not only more systematic and rigorous research into this field, but also long-term accounts which follow children well into their teens when their languages have become fully established but their use, preference and subsequent competence may be influenced by affective variables. Our understanding of trilingual competence would also benefit from more trilingual data or, if this is genuinely not obtainable, more data from trilinguals which might point towards an explanation of why most non-monolingual speech of trilinguals seems to be influenced bi-directionally rather than tridirectionally. The question of language dominance in different groups of trilinguals might profitably be pursued from a variety of angles, looking at various aspects related to its emergence and manifestation, as well as factors determining it. 


\subsection{Trilingualism through schooling}

The second type of research into trilingualism looks at bilingual children's acquisition of the third language through schooling. Studies of this kind have been carried out with linguistic minority children in the United States (e.g. Thomas 1988, Klein 1995), Canada (Bild \& Swain 1989, Genesee 1998)), Belgium (Jaspaert \& Lemmens, 1990), and he Basque Country among others(Valencia \& Cenoz 1992, Cenoz \& Lindsay 1996, Cenoz 1998). In contrast to the largely observational studies outlined in the previous section the ones reported about here are all of an experimental nature. These studies differ with regard to their research methodologies and testing procedures, as well as in the languages involved - although in most cases either English or French is the third language. Several researchers have posed, in various forms, the same question: does bilingualism favour the acquisition of a third language? It is suggested that bilinguals may indeed have certain advantages with respect to general language proficiency and therefore be able to acquire a third language more easily than a monolingual learns a second language. A related question asks about the nature of the difference between second and third language acquisition. Thomas (1988) discusses the role played by metalinguistic awareness in the case of monolingual and bilingual performance. In her examination of learners she found that bilinguals had developed more sensitivity to language as a system, which helped them in the solution of certain linguistic tasks, apart from also possessing enhanced lexical knowledge. Zobl (1993) focused on the bilinguals' learning procedure when acquiring a third language and found that the subjects in his study followed less conservative pathways than monolinguals. In the majority of cases the participants were learners in their teens who had been in a formal educational environment for years. The importance of formal learning of language is also highlighted by Thomas (1988), who claims that those bilinguals who possessed literary skills in both their languages performed better in the kind of tests that required manipulation of language.

Some of the research carried out in the Basque Country (Cenoz \& Lindsay 1996) was concerned with the optimum age and the most suitable methodologies for introducing the third language. This investigative project involved eight-year-old Basque-Spanish bilinguals. Contrary to the Thomas (1988) subjects, these children had only very limited biliteracy experience, and it is therefore not surprising to find that psychological, social and pedagogical factors, as well as contextual elements such as positive attitudes in the community towards learning English, parental support and a good teacher, were of particular importance. 
Valencia \& Cenoz's (1992) large-scale study involved older secondary school pupils in the Basque Country learning English and also pursued the question of what relationship exists between bilingualism and third language acquisition. Their subjects were assessed with regard to dependent variables which were measured via various English achievement tests, and in relation to two types of independent variables. The first of these related to the subjects' bilingualism (early bilingualism, family bilingualism, educational bilingualism, sociocultural bilingual background and self-assessment of their competence in Basque), whereas the second kind of independent variables involved four measurements of social motivation (attitude towards learning, effort, residence in an English-speaking country and English tuition outside school). The authors' first hypothesis was that bilingualism will have a positive effect on third language acquisition, an assumption which their results support. Their second postulate is that the effect of bilingualism on the learning of the additional language will be mediated by the role of social motivation and, again, their conclusions uphold this claim. Valencia \& Cenoz's research goes beyond what had previously been done in, for instance, the Canadian context. They develop a structural model with the three latent variables, bilingualism, motivation and achievement, which shows a causal path linking bilingualism through social motivation with achievement in English. Research of the kind outlined here is of only indirect relevance to the exploration of trilingual competence. But it draws our attention to a number of variables which come into play in the acquisition process, and it provides an indication that there are various factors which could be decisive in shaping the resulting trilingual competence at different times or ages.

As usual, when discussing the age factor in language learning it is not possible to discern clear cut-off points between the infant, the child and the older trilingual, or between simultaneous and subsequent trilingualism, or between natural acquisition and acquisition as a result of tuition. Many questions remain unanswered, such as for instance: How should we view the child who acquires three languages to an age-adequate degree of competence and then picks up literacy and other learnt language skills in one, two or all of his/her languages to either an equal or unequal extent? Which are the variables that determine the further development - or attrition of his/her languages? Which of the variables will be the more important ones, the attitudinal and personality-related ones, or those associated with (or deriving from) formal learning experience? Ultimately the multiple variables cannot be disentangled, just as the abovementioned distinctions (between types of subjects) ultimately remain theoretical constructs. 


\subsection{Linguistic behaviour of trilingual immigrants}

Clyne's(1997) report on an on-going project about language processing in trilinguals in Australia represents the third type of research. It promises to be of particular value to our knowledge of trilingualism because it is both a long-term and large-scale study and it involves different combinations of languages. His subjects have a bilingual family background or come from a bilingual environment, and acquired English after emigrating to Australia. They represent three different sets of language combinations: two of these include groups of languages which are, relatively speaking, more closely related (Dutch-German-English and Italian-Spanish-English), and the third combination consists of a set of languages which are less directly related (Hungarian-German-English). These three sets of languages have varying degrees of distance from English and from one another. But in all cases English is the general lingua franca, the language of overarching importance, whereas one, or both, of the subjects' other language(s) is/are associated with their cultural identity. Clyne examines the interlingual strategies employed by his trilingual subjects, and he notices that some of these strategies are similar to those which have been identified by second language acquisition researchers working on positive and negative transfer, for example the identification by the learner of contrasts and interlingual correspondences. Clyne speaks about the trilingual's "multilateral competence" which encompasses linguistic as well as procedural knowledge and finds evidence for it in various aspects of trilingual behaviour. Thus he describes conversion rules which are applied between closely related languages and which may in some cases result in compromise forms. He describes interlingual identification by the trilingual based on correspondences between two of the trilinguals' languages and even finds "a tendency towards triple interlingual identification" (Clyne 1997:110), i.e. instances of transfer of a linguistic feature which is shared by two of the trilingual's languages to his or her third language. Much of Clyne's evidence for multilateral competence comes from derivational morphology, particularly where Dutch and German are used. There are also some examples involving lexis and phonology in the case of Spanish and Italian, as well as other instances showing how the same form is shared by the two languages.

Clyne's section on code-switching contains illustrations of intrasentential switching between two languages, and also cases of trilingual switching. In this context he points towards the widespread phenomenon of English lexical items being transferred into other languages and that 
such items act not only as a bridge between English and another language but also between other languages. A trilingual sentence may come about when the speaker starts an utterance in one language, and then inserts an English item which then triggers a switch to the third language. In other words, the English item causes the speaker "to lose linguistic orientation" (Clyne 1997: 110), and the wrong switch-back is then effected. Most of the data discussed comes from the Dutch-German-English and Italian-Spanish-English trilinguals. In contrast, Clyne found that English lexical items transferred into German or Hungarian did not trigger switches between these two languages. His explanation is that the English items were fully integrated morphologically into Hungarian, thus making them sufficiently distinct to the speaker. The three linguistic phenomena on which he focused lead him to conclude that bilinguals and trilinguals use the same kinds of mechanisms and processes, but that these are more complex when three languages are involved. As regards the relative importance of the trilingual's three languages, Clyne observed that English was generally employed more frequently and in a wider variety of domains and functions, and also that one of the other languages will often be used to a greater extent than the other one. The relative influence of the languages on one another depends on a number of factors, such as the amount of use, whether there is more or less distance between them, and the role each language plays in the individual's triculturalism. Also, typological considerations come into play when he concludes that "trilinguals will be trilingual in different ways" (Clyne 1997: 113), adding that some trilinguals were more like bilinguals who have two distinct standard languages plus a non-standard variety regarded as part of one of them in some ways (the Spanish-Italian-English speakers, immigrants from Latin America). Other trilinguals were more like double bilinguals, with two pairs of languages where each pair has a special relationship with English rather than with the other languages. Clyne is primarily concerned with what trilinguals do, i.e. with trilingual processing and production and suggests that much the same mechanisms and processes are employed by bilinguals and trilinguals alike but that linguistic distance between the languages involved is an important factor. Some of the explanations he offers for his data in terms of multilateral competence suggests that there are features which can be seen as being quite unique to trilinguals and which can be seen as forming part of trilingual competence, such as the "triple interlingual identification" and the establishment of a special triangular relationship between the three languages, with English taking up a seemingly dominating, pivotal position. The question which presents itself is whether these features are the result of quantitative differences only or whether an element of qualitative difference is involved as well. 


\section{Bilingual and trilingual competence}

Various models of the structure of language competence have been developed, trying to link the linguistic view of language with a communicative one, and also attempting to explain how linguistic skills and knowledge are integrated and put into use. Canale \& Swain's (1980) model proposes four main components: linguistic, sociolinguistic, discourse and strategic competence. Similarly, the model Bachman (1990) puts forward takes cognisance of the dualism of language competence, consisting of linguistic constituents (e.g. grammar) and the pragmatic aspect which acknowledges language as a means of establishing social relationships and communicating information.

Grosjean's $(1985,1992)$ sees the bilingual as making use of his or her two languages depending on the requirements of the situation and as we know, these will be determined, amongst other factors, by the topic or place or interlocutor, and may be mediated by social or psychological variables such as perceived social appropriateness to use Language A rather than Language B, the wish to include or exclude someone in the conversation, the desire to dominate a linguistically weaker interlocutor or to defer to him/her etc. Bilinguals may use both their languages simultaneously in the form of frequent switching or borrowing. Therefore the language competence of the bilingual speaker must be assessed in terms of his or her total language repertoire, and not in relation to individual languages only. This view can easily be extended to trilingualism. Trilingual language competence can then be said to contain the linguistic aspects, i.e. vocabulary and grammar, from the three language systems, and also the pragmatic component, consisting of sociolinguistic, discourse and strategic competences pertaining to the three languages involved. In addition, it includes the ability to function in bilingual or trilingual contexts, which require decisions on code choice and code-switching. Trilingual competence enables speakers to create their own linguistic means in order to master particular communicative situations

It is this type of competence which points towards important differences between monolinguals on the one hand and bilinguals and trilinguals on the other. For bilinguals or trilinguals it is normal to move between different languages, switching, mixing and borrowing as they do so. Indeed, we must consider code-switching to be an essential speech strategy of bilinguals and trilinguals. It is curious, however, that when they are asked to judge their own competence, they tend to ignore this ability and instead they focus on linguistic aspects, criticising their own 
grammatical or lexical shortcomings in one or two or all of their languages, seemingly applying monolingual standards. In the longer term, this perceived inadequacy may lead them to develop strategies to avoid using their weaker language or reduce their use to a limited range of domains. Similarly, powerful psychological forces, such as rejection of a particular speaker or culture, or problems of finding one's own identity, may cause a speaker to abandon one or more of his or her languages. These observations are based on personal experience and also my reading about bilinguals and multilinguals who fall into the first four groups outlined in section one. It would be intriguing to know whether the same kind of perceptions of multilingualism and language competence are also held by multilingual speakers in the multilingual cities of Asia or Africa.

The fact that both bilingual and trilingual speakers make linguistic adjustments according to new situations, environments and perceptions does not mean that their overall communicative competence will be affected. Rather, a redistribution of functions assigned to each of their languages and changes in the proficiency in one or two of their languages may be the result of increased or decreased use of the language(s) concerned, so that active bilinguals and trilinguals become passive ones, or vice versa. Yet in spite of these adaptations they remain fully competent speaker-hearers within their linguistic environment and its communicative requirements.

A related area of differences between monolingual and bilingual or trilingual competence concerns the structure and organisation of the trilinguals' competence with regard to their speech modes. Grosjean (1992) proposes that we should see the bilingual's speech modes in terms of end points on a scale. In this view, a bilingual may move from a monolingual speech mode when talking to a monolingual speaker, where he uses one language only while the other remains deactivated, and then change along the continuum to the bilingual speech mode, where he makes use of both his languages when speaking to another bilingual, in the form of frequent switching and borrowing. It is difficult to see how this two-dimensional model could be employed to explain the trilingual's ability to move between one, two or three codes.

The idea of languages being activated and deactivated throws up a number of intriguing questions. There is, first, the fundamental issue of what mechanisms, if any, enable the individual to switch languages, with regard to both perception and production. More specifically, one might ask: To what degree is one of the bilingual's languages deactivated 
when the subject is in a monolingual mode? And vice versa, to what extent, and in what relation to each other, are both languages activated when he/she is in a bilingual mode? And in trilinguals, is it a case of all three languages being activated simultaneously, or are there different degrees of activation, or deactivation, of the two languages while the third one is being used?

If one transfers Grosjean's notion of speech modes to trilinguals, their three speech modes (monolingual, bilingual and trilingual) would then, at least in theory, have 7 different constellations (as compared with the monolingual's 1 and the bilingual's 4): the monolingual modes of languages $\mathrm{A}, \mathrm{B}$ and $\mathrm{C} ; 3$ bilingual modes (involving combinations of $\mathrm{A}+\mathrm{B}, \mathrm{A}+\mathrm{C}$ and $\mathrm{B}+\mathrm{C})$; and one trilingual mode involving all three languages $\mathrm{A}+\mathrm{B}+\mathrm{C}$. There does not seem to be any focussed documentary evidence for this, but in practice (and judging from the examples of trilinguals' speech production) trilinguals rarely make use of all 7 modes, particularly after the emergence of the dominant language. In my own studies, which involved two noncommunity languages, German and Spanish, and the community language English, the two trilingual children were observed to use either one of their three languages, or they used English plus one of the other languages. There were never any situations where all three languages were used simultaneously even when several trilinguals sharing the same languages were taking part in the same conversation. Similarly, and apart from some cases of borrowing, there were no examples of the three languages being used in the same utterance, and only very early data (taken at the time when the community language had not yet been fully established) showed mixing of the two home languages, Spanish and German, i.e. the languages which were to become the non-dominant ones. Widdicombe (1997) also remarked on the absence of evidence of a trilingual speech mode in the extensive data she collected given the fact that the child, in her estimation, had had roughly equal exposure to his three languages in terms of hours per day during the first four years of his life and that he must have been aware that his parents spoke three languages even though only two of them were consistently used by them in the home. Clyne (1997), as we have seen, does give some examples of speech production that is unmistakably trilingual but in his assessment of trilingual speech behaviour he notes a tendency for trilinguals to behave more like bilinguals, or double bilinguals. The tendency for bidirectionality involving the dominant language seems to apply to the kind of trilinguals who have been reported about in the studies discussed above. To what extent this might be a general characteristic of trilinguaisms can only be answered after more is know about language use and 
speech behaviour in type v) trilinguals, i.e. those who live in multilingual communities and habitually use three codes.

\section{Trilingualism and language processing}

In this section a brief and eclectic look is taken at the mechanisms underlying speech production. It is obvious that trilingualism involves considerable linguistic complexity, not only as a result of the number of different linguistic systems and the ways in which they can interact, but also in terms of how they are processed. In this respect, too, the fundamental distinction between monolinguals and bilinguals is one of kind, i.e. qualitative, and the difference between bilinguals and trilinguals may involve more than just a quantitative one.

Explanations of language processing in bilinguals have been put forward by several researchers, both as compared with monolingual processing and with reference to various bilingual speech phenomena such as mixing, responding in a different language from the language of the interlocutor, and spontaneous translation. Both Paradis (1985) and Perecman (1989) see language processing as taking place on different levels: a prelinguistic conceptual level which reflects properties of the human mind and is common to both of the bilingual's languages because it is independent of language, and then the functionally different semantic-lexical level where "units of meaning in each language combine conceptual features in different ways" (Paradis 1985: 9). Perecman (1989) believes that the distinction between a prelinguistic conceptual representation and a properly linguistic representation is particularly relevant in accounting for the ability to translate since, she argues, "translations must make reference to a common level of information processing, and the conceptual level is the only plausible candidate" (Perecman 1989: 236) She outlines a neurolinguistic model for language processing in bilinguals and then accounts for mixing in terms of the framework of this model. The model assumes a hierarchy of processing, at the top of which there is the conceptual level with shared processing of language-independent information. Below that, there are various linguistic strata the semantic-lexical, the syntactic, the phonological and the phonetic-articulatory levels. Perecman assumes that in monolinguals, where the conceptual system feeds into only one linguistic system, the processing routines from the conceptual down to the phonological forms

have become automatized. In contrast, the conceptual system in bilinguals has two options with regard to lexical-semantic processing, and it can be encoded in two different linguistic systems. Perecman's suggestion is that the processing routines are less automatic for the bilingual, and 
that the distinction between levels of representation will be more marked. The model is evidently meant to apply to multilingual as well as bilingual processing, as Perecman stipulates (1989: 233) that multiple languages are unified in a single system at the prelinguistic conceptual level, that they are strongly linked at the semantic-lexical one, and that the links are progressively weaker as processing moves from the lexical-semantic to the articulatoryphonetic rank. Evidence for this are observations that language mixing occurs more frequently at the lexical-semantic than at the phonetic-articulatory level where, Perecman argues, the links between the systems are weakest. She refers in her concluding remarks to the fact that some authors do not make a distinction between bilinguals and polyglots and she herself does not express any clear view in this regard either. Again it needs to be said that only more empirical research will shed light on the question of whether there is a distinction at all to be made with respect to psycholinguistic and/or neurolinguistic processing, and whether it would be of relevance. It seems to me, however, that we can assume that the various mental and linguistic operations become increasingly more complex the more languages are involved. Following Paradis' (1987) suggestion that distance or relatedness of a bilingual's languages may result in separate or joint storage it might be necessary to talk about such complexity as being relative and variable, depending on the typologies of the languages a trilingual has to process. The larger the number of linguistic systems at work, the higher the number of possible combinations and interactions of these at the processing level, and the larger the possible variations due to language dominance of one or two languages and other mediating psychological factors. For this reason one might argue that, at any rate with regard to some aspects, trilingual competence can be seen as different from bilingual competence rather than more of the same.

Another area where we may look for differences between monolinguals, bilinguals and trilinguals concerns metalinguistic awareness. Bialystok (1991) points out that there exists some confusion about the term, as it is interchangeably used to refer to: (a) tasks, such as making a judgment on well-formedness or making repairs; (b) skills, for instance the learners' ability to focus on language forms; and (c) levels of awareness, such as when a learner is aware of the forms and functions of language being manipulated. Bialystok develops a conception of metalinguistic awareness that involves all three aspects, and she then applies this metalinguistic conception to the establishment of a model of language development in bilingual children. This focus implies that the model attempts to account for change. Language processing is described in terms of two components: the component which enables mental representations to become more explicit and structured she calls "analysis of linguistic knowledge"; and the second 
component is responsible for "control of linguistic processing" (Bialystok 1991: 116). The author looked at the ability of monolinguals and bilinguals to solve problems in three different language domains, and she found significant differences in each case. For instance, in the discussion of experiments involving oral language use she concluded that bilingual children have heightened metalinguistic awareness because they routinely pay attention to language form (i.e. which language is spoken) in order to make decisions on their own language choice. This means that additional demands are placed on their control abilities, in comparison with the demands made of monolingual children. With regard to trilinguals the experience of three different languages also results in further enhanced awareness of the analysis and control components of processing to enable the speaker to make the right choices and respond in linguistically and communicatively adequate ways. In bilinguals the choices involve thre choices: language A or B or both simultaneously. Trilinguals' choices are potentially considerably more numerous as the discussion on speech modes above showed, but in practice there seem to be a number of mediating social and psychological factor at work which restrict the number of choices. On the basis of her own evidence and that of others, Bialystok argues that bilingual children ultimately and inevitably process language differently from monolingual children (1991: 139). Clearly, more empirical work is needed before we can tell for sure what happens in respect of trilingual children. Work done on bilingual language processing represents a suitable starting point for such an undertaking.

\section{Conclusion}

The aim of this article has been twofold: on the one hand, to give a state of the art overview of studies into trilingualism and on the other, to look at trilingual competence with a view to comparing it with bilingual competence. and to try to ascertain the extent to which any of the differences are amenable to explanation in quantitative or qualitative terms. I have looked for possible evidence from various areas of research: firstly, different kinds of case studies of trilingual acquisition and use; secondly, explanations of language competence in bilinguals, particularly with regards to code-switching; and thirdly, some discussions of bilingual language processing and metalinguistic awareness.

The case studies involving primary and secondary trilinguals lead one to assume that in terms of acquisition and language use trilinguals function in similar ways to bilinguals, except for differences which can be attributed to an increased linguistic load in trilinguals. With respect to 
the trilinguals' communicative competence, roughly the same could be said, particularly if the focus is on the linguistic component; but when the pragmatic component is included one begins to realise that the strategies a trilingual may adopt become quite complex. If, in addition to communicative competence, one considers the mechanisms and processes which seem to be involved in the selection of the appropriate language, and also language mixing, switching and borrowing - either consciously or unconsciously -, then it becomes apparent that a comparison between bilinguals and trilinguals may show up differences which go beyond quantitative ones. The case studies which are available can contribute to our understanding of certain aspects of multilingualism, but at present we lack a sufficient number, as well as greater variety, of such studies. The fact that, to my knowledge, there is virtually no empirical research on language processing in trilinguals is also a serious shortcoming. Similarly, studies which focus on the effect of socio-cultural and affective variables that may make an impact on trilinguals at different times and in various ways would be welcome, as they could show to what extent (if at all) they impinge on trilingual competence. The most promising current developments appear to come from work which analyses the linguistic behaviour of trilinguals and which attempts to cross the boundaries between second language acquisition research and bilingualism studies. I believe that trilingualism, of whatever kind, is likely to gain greater prominence in the future. It is to be hoped that this trend will be mirrored by corresponding advances in our understanding of the processes and mechanisms involved.

Received: May, 1998; revised: August, 1998' ; accepted: January, 1999

$\underline{\text { References }}$

ARNBERG, L. (1987) Raising children bilingually: the pre-school years, Clevedon: Multilingual Matters.

BACHMAN, L.F. (1990) Fundamental considerations in language testing, Oxford: Oxford University Press.

BAETENS BEARDSMORE, H. (1982) Bilingualism: Basic principles, Clevedon: Multilingual Matters. BIALYSTOK, E. (1991) Metalinguistic dimensions of language proficiency. In E. Bialystok (ed.) Language processing in bilingual children (pp. 113-140). Cambridge: Cambridge University Press. BILD, E.R. \& SWAIN, M. (1989) Minority language students in a French immersion programme: their French proficiency. Journal of Multilingual and Multicultural Development, 10 (3), 255-274.

\footnotetext{
${ }^{1}$ The author is aware that advances relevant to this article in the areas of bilingual processing and language activation have been made after this text was revised in 1998.
} 
CANALE M. \& SWAIN, M. (1980) Theoretical bases of communicative approaches to second language teaching and testing. Applied Linguistics, 1, 1-47.

CENOZ, J. (1998) Multilingual education in the Basque Country. In J Cenoz and F. Genesee (eds.) Beyond bilingualism. Multilingualism and multilingual education (pp. 175-191). Clevedon: Multilingual Matters.

CENOZ, J. \& GENESEE, F (1998) Pycholinguistic perspectives on multilingualism and multilingual education. In J.Cenoz and F. Genesee (eds) Beyond bilingualism. multilingualism and multilingual education (pp. 16-32). Clevedon: Multilingual Matters.

CENOZ, J. \& LINDSAY, D. (1996) English in primary school: teaching a third language to eight year olds in the Basque Country. Cuadernos de Filología Inglesa, 5 (1), 81 -102.

CLYNE, M. (1997) Some of the things trilinguals do. The International Journal of Bilingualism, 1 (2), 95-116.

COOK, V. (1992) Evidence for multi-competence. Language Learning, 42, (4), 557-591.

COOK, V. (1993) Wholistic multi-competence: jeu d'esprit or paradigm shift? In B. Kettemann and W.W. Wieden (eds.) Current issues in European second language research (pp. 4-8). Tübingen: Gunter Narr.

ELWERT, W.T. (1973) Das zweisprachige Individuum: ein Selbstzeugnis . Studien zu den romanischen Sprachen Band IV (1-81). Wiesbaden, Franz Steiner Verlag.

GENESEE, F. (1998) A case study of multilingual education in Canada. In J. Cenoz \& F. Genesee (eds.) Beyond bilingualism: multilingualism and multilingual education (pp. 243-258). Clevedon: Multilingual Matters.

GROSJEAN, F. (1985) The bilingual as a competent but specific speaker-hearer. Journal of Multilingual and Multicultural Development, 4 (6), 467-477.

GROSJEAN, F. (1992) Another view of bilingualism. In R.J. Harris (ed.) Cognitive processing in bilinguals (pp. 51-62). Amsterdam: Elsevier Science Publishers.

HARDING, E. \& RILEY, P. (1986) The Bilingual family: a handbook for parents. Cambridge: Cambridge University Press.

HAUGEN, E. (1956) Bilingualism in the Americas. Alabama: American Dialect Society.

HELOT, C. (1988) Bringing up children in English, French and Irish: two case studies. Language, Culture and Curriculum, I (3), 281-287.

HOFFMANN, C. (1985) Language acquisition in two trilingual children Journal of Multilingual and Multicultural Development, 6 (6), 479-495.

HOFFMANN, C. (1991) An Introduction to bilingualism. London: Longman.

HOFFMANN, C. (1992) La evaluación de la producción lingüística del niño bilingüe. In F. Etxeberría \& J. Arzamendi (eds) Bilingüismo y adquisición de lenguas. Actas del IX Congreso Nacional de AESLA. Servicio Editorial de la Universidad del País Vasco, Bilbao, 329-351. 
HOFFMANN, C. \& WIDDICOMBE, S. (1998) The language behaviour of trilingual children: developmental aspects. Paper presented at the EUROSLA VIII Conference, Paris, France.

JASPAERT, K. \& LEMMENS, G. (1990) Linguistic evaluation of Dutch as a third language. In M. Byram \& J. Leman (eds) Bicultural and trilingual education The Foyer model in Brussels (pp. 30-56). Clevedon: Multilingual Matters.

JEßNER, U. (1997) Towards a dynamic view of multilingualism In: M. Pütz (ed.) Language choices: Conditions, constraints and consequences (pp. 17-30). Amsterdam: John Benjamin.

KLEIN, E. (1995) Second versus third language acquisition: is there a difference? Language Learning, 45 (3), 419-466.

OKSAAR, E. (1977) On becoming trilingual. In C. Molony (ed.) Deutsch im Kontakt mit anderen Sprachen (pp. 296-306).Kronberg: Scriptor Verlag.

OKSAAR, E. (1983) Multilingualism and multiculturalism from the linguist's point of view. In T. Husén and S. Opper (eds) Multicultural and multilingual education in immigrant countries (pp. 17-36). Wenner Gren Symposium Series, Vol. 38, Oxford: Pergamon Press.

PARADIS, M. (1985) On the representation of languages in the brain (pp. 1-40) Language Sciences, 7, $1-40$.

PARADIS, M. (1987) The assessment of bilingual aphasia. Hillsdale: Erlbaum.

PERECMAN, E. (1989) Language processing in the bilingual: evidence from language mixing. In K. Hyltenstam and L. Obler (eds.) Bilingualism across the lifespan (227-244). Cambridge: Cambridge University Press.

SKUTNABB-KANGAS, T. (1984) Bilingualism or not. Clevedon: Multilingual Matters.

THOMAS, J. (1988) The role played by metalinguistic awareness in second and third language learning .Journal of Multilingual and Multicultural Development, 9 (3), 235-246.

VALENCIA, J.F. \& CENOZ, J. (1992) The role of bilingualism in foreign language acquisition. Journal of Multilingual and Multicultural Development, 13 (5), 433-449.

WIDDICOMBE, S. (1997) Code-switching, coining and interference in trilingual first language acquisition: as case study. Unpublished MSc dissertation, University of Aston, Birmingham, U.K.

ZOBL, H. (1993) Prior linguistic knowledge and the conservation of the learning procedure: grammaticality judgments of unilingual and multilingual learners. In S.M. Gass \& L. Selinker (eds) Language transfer in language learning (pp. 176-196). Amsterdam,: John Benjamins. 